\title{
A temperature reading of COVID-19 pandemic employee agility and resilience in South Africa
}

\begin{tabular}{|c|c|}
\hline $\begin{array}{l}\text { Authors: } \\
\text { Cristy Leask }^{1} \\
\text { Shaun Ruggur }\end{array}$ & \\
\hline $\begin{array}{l}\text { Affiliations: } \\
{ }^{1} \text { Graduate Sch } \\
\text { College of Lav } \\
\text { Management } \\
\text { KwaZulu-Nata } \\
\text { South Africa }\end{array}$ & $\begin{array}{l}\text { ool of Business, } \\
\text { and } \\
\text { University of } \\
\text { Durban, }\end{array}$ \\
\hline $\begin{array}{l}{ }^{2} \text { School of Ma } \\
\text { and Governan } \\
\text { Law and Man } \\
\text { University of } \\
\text { Durban, South }\end{array}$ & $\begin{array}{l}\text { nagement, IT } \\
\text { ce, College of } \\
\text { gement, } \\
\text { waZulu-Natal, } \\
\text { Africa }\end{array}$ \\
\hline $\begin{array}{l}\text { Project resear } \\
03 / 2020\end{array}$ & ch number: \\
\hline $\begin{array}{l}\text { Correspondin } \\
\text { Cristy Leask, } \\
\text { leaskc@ukzn. }\end{array}$ & $\begin{array}{l}\text { author: } \\
\text { c.za }\end{array}$ \\
\hline $\begin{array}{l}\text { Dates: } \\
\text { Received: } 10 \\
\text { Accepted: } 23 \\
\text { Published: } 27\end{array}$ & $\begin{array}{l}\text { lov. } 2020 \\
\text { May } 2021 \\
\text { uly } 2021\end{array}$ \\
\hline $\begin{array}{l}\text { How to cite th } \\
\text { Leask, C., \& RL } \\
\text { (2021). A tem } \\
\text { reading of CO } \\
\text { pandemic em } \\
\text { and resilience } \\
\text { SA Journal of I } \\
\text { Psychology/SA } \\
\text { Bedryfsielkuno } \\
\text { a1853. https:/ } \\
\text { 10.4102/sajip. }\end{array}$ & $\begin{array}{l}\text { is article: } \\
\text { ggunan, S. } \\
\text { gerature } \\
\text { /ID-19 } \\
\text { loyee agility } \\
\text { in South Africa. } \\
\text { ndustrial } \\
\text { Tydskrif vir } \\
\text { le, 47(0), } \\
\text { /doi.org/ } \\
\text { v47i0.1853 }\end{array}$ \\
\hline $\begin{array}{l}\text { Copyright: } \\
\text { (c) 2021. The A } \\
\text { Licensee: AOS } \\
\text { is licensed unc } \\
\text { Creative Comr } \\
\text { Attribution Lic }\end{array}$ & $\begin{array}{l}\text { uthors. } \\
\text { S. This work } \\
\text { ler the } \\
\text { nons } \\
\text { ense. }\end{array}$ \\
\hline Read online: & \\
\hline 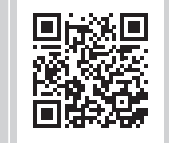 & $\begin{array}{l}\text { Scan this QR } \\
\text { code with your } \\
\text { smart phone or } \\
\text { mobile device } \\
\text { to read online. }\end{array}$ \\
\hline
\end{tabular}

Orientation: Employee agility and resilience are central to the flourishing of employee and organisational life. The coronavirus disease 2019 (COVID-19) pandemic amplified stressors and added new challenges for employees in South Africa. The study reported here provides a temperature reading of the agility and resilience of South African employees in the context of the pandemic.

Research purpose: The aim of this study was to engage in a temperature reading of South African employees' agility and resilience during the COVID-19 pandemic.

Motivation for the study: The study was motivated by the need to understand how South African employees fare in terms of their agility and resilience levels in the context of profound social and economic disruptive events such as the COVID-19 pandemic.

Research approach/design and method: A cross-sectional survey design was used employing quantitative methodologies. A total of 185 permanently employed respondents from South Africa were conveniently sampled. Descriptive and inferential statistics were used to analyse the data.

Main findings: Whilst respondents reported high resilience and agility capacity, the findings also suggest that respondents' gender, age, upskilling intentions, size of employer, organisational communication and individual renewal strategies influence their resilience and agility behaviours.

Practical/managerial implications: The study prompts a discussion on how practitioners can better serve the wellness agenda of organisational life during sustained periods of organisational stress.

Contribution/value-add: This study extends the theoretical and practical debate on employee agility and resilience in South African context.

Keywords: employee agility and resilience; COVID-19; South Africa; impact of COVID-19 on employees; gender; COVID-19 impact on organisations.

\section{Introduction}

The coronavirus disease 2019 (COVID-19) pandemic has had a profound impact on the economy, with significant psychological and social effect on global populations. The scope of COVID-19 warrants a classification as a 'grand challenge' (Bacq, Geoghegan, Josefy, Stevenson, \& Williams, 2020). Given the global state of mental health because of COVID-19, a united cooperation in research for shared data access, expertise and capacity-building is required as a response to this 'grand challenge'.

Debates on whether to lock down cities or countries have revolved around economic concerns primarily, with less focus on the psychological and sociological consequences of these lockdowns. Different patterns of responses, including employers, employees and states, are contextually dependent on the unique cultural, economic, social and political features of these places. Hence, we find that the Asian response differs significantly from that of the United States, for example. Even within a continent, diversity of experiences and responses occurs as is the case in Europe (Balmford, Annan, Hargreaves, Altoè, \& Batemen, 2020). Context, therefore, matters and our research is embedded in a South African context, which is characterised by high levels of unemployment, poverty and inequality pre-COVID-19. Some of the South African business responses to COVID-19 have been to focus on economic survival by ceasing production, re-structuring and cutting expenses, especially staff wages, which has led to significant job losses. 


\section{Literature review}

South Africa presents an interesting case study to measure employee agility and resilience levels for the following reasons. The country has a high unemployment rate when benchmarked globally. The pandemic has exacerbated this rate to almost 50\% (Statistics South Africa, 2020b), making it one of the highest in the world. Each employed South African in the formal sector on an average supports up to three other adults, making it one of the highest dependency rates in the world. Compounding this are some of the highest rates of (racialised) income inequality in the world (Statistics South Africa, 2020a). South Africans experience high rates of violent crime, chronic stress, violence against women, racism and trauma, which perhaps could only be rivalled by some South American countries (Lamb, 2019; Peltzer, 2000). Prior to COVID-19, the focus of the South African government was developing entrepreneurship and the informal and small, medium and micro enterprises (SMMEs) sector as means of job creation, skills development and the economy (Urban \& Ndou, 2019). COVID-19 has devastated up to $60 \%$ of this sector (Kalidas, Magwentshu, \& Rajagopaul, 2020).

Whilst the COVID-19 pandemic is significant, the South African experience of the human immunodeficiency virus (HIV) and tuberculosis (TB) epidemics (which have had higher death rates), which arguably caused deeper restructuring of society, is an experience that sets it apart from many other countries. In other words, South Africans are used to economic and social hardships. The sudden and deep disruptions of the lockdown jarred an already fraught and fragile South African society.

It is against this background that we do a 'temperature reading' of the agility and resilience levels of permanently employed South Africans during the current pandemic. Our research design is analogous to a physical temperature reading that is conducted to determine the state of one's physical health at a particular moment in time. We want to ascertain the levels of employee agility and resilience of employees during profound social disruption of the COVID-19 pandemic in a rapid way that gives an overall sense of the 'well-being' (as measured by agility and resilience levels) of South African employees. There is less focus on developing complex statistical models to determine and assess causality, and the focus is more on ascertaining an overall and quick sense of agility and resilience levels at a particular moment in time. An 'abnormal' reading is an indicator that something may be amiss, or even relatively normal indicators during abnormal times may allow us to conjecture as to why this may be the case. Most of the temperature reading studies were conducted outside South Africa, and inferences were made from these global studies (Alves et al., 2020; Helgeson et al., 2020).

At the time this survey, no other study assessing these measures during the pandemic was conducted. Recently, a number of COVID-19-related employee surveys have been conducted in South Africa but none has assessed agility and resilience levels of employees (Cant, 2020; Matli, 2020). Temperature reading surveys are important during times of rapid change because they point to potential areas of concern for scholars and practitioners, whilst at the same time inviting reflection on how to better refine survey and research design for future studies (Cozby \& Bates, 2015). The urgency of the context also means that as scholar-practitioners, it is important for us to act quickly so that we can best position our professions to serve both organisations and employees in South Africa.

In response to the COVID-19 pandemic, employees in the formal sector have had to work from home, change workrelated processes, juggle family demands, especially as they navigate the balance of multiple roles across work with personal lives. It is not surprising that a plethora of both popular and scholarly works on resilience and agility have emerged during the lockdown, as scholars and practitioners attempt to make sense of organisational and employee experiences of the pandemic (Childress, 2020; Chong, Handscomb, Williams, Hall, \& Rooney, 2020; Havnen et al., 2020). COVID-19 and the resulting social distancing policy had an unprecedented negative impact on organisational financial performance globally and nationally (Ozili \& Arun, 2020).

Many organisations are facing challenges of work re-structuring, re-organisation and re-pivoting so that they become fit for the purpose. Organisational survival and effectiveness depend on the ability of organisations and employees to withstand and adapt to significant challenges, that is, on their resilience. Resilience in organisations has been acknowledged as a vital competitive advantage, and as a result, research on how to promote and improve resilience amongst employees is increasing (Bardoel, Pettit, De Cieri, \& McMillan, 2014; Lengnick-Hall, Beck, \& Lengnick-Hall, 2011). The increased interest in employee agility and resilience stems from a wish to strengthen organisational systems and infrastructure, and to ensure organisational sustainability, which depend on the extent to which employees are able to maintain performance levels (Lengnick-Hall et al., 2011). Agility and resilience skills help employees deal with change more effectively and positively. Organisations with high levels of agility have workforces that are innovative, fast to adapt to change and flexible (Muduli, 2013).

Against this backdrop of the impact of COVID-19 on organisations and employees, time is of the essence for industrial-organisational (I-O) psychologists to urgently intervene with evidence-based solutions and thus dissuade organisations from the lure of the 'magic bullet' (Rotolo at al., 2018). The purpose of the current research study was to conduct a point in time temperature reading of employees' agility and resilience to enable nuanced and tailored interventions. During this crisis, it is an opportunity for the South African I-O psychology community to contribute to understanding the ways in which the pandemic is shaping 
organisational life for South African employees with relevant credible, transparent and ethical research (Van Zyl \& Junker, 2019).

Employee agility and resilience have gained attention in the literature through investigating organisational change and information technology (IT) system implementation (Breu, Hemingway, Strathern, \& Bridger, 2002). Qin and Nembhard (2010) defined workforce agility as the ability of employees to respond strategically to uncertainty with an emphasis on its greater salience in enterprises which rely heavily on the workforce to transfer cutting-edge technologies into products. Muduli (2013) conceptualised an agile workforce as well-trained and flexible, adapting quickly and easily to new opportunities and market circumstances. Employee agility is beneficial to the organisation's performance (Muduli, 2013) and the ability to navigate change (Warner \& April, 2012). Organisational agility is considered as a contributor to a company's success, and thus employee agility would be valued by the organisation (Podsakoff, Whiting, Podsakoff, \& Blume, 2009). Thus, employee agility and resilience will be a key ingredient to enable organisations to re-organise for survival. The current context of deep disruption may be the COVID-19 pandemic, but further deep societal disruptive events will continue. These may range from further pandemics to unknown and unanticipated future societal upheavals. Measuring levels of agility and resilience during the current societal crisis may allow us to extrapolate how organisations and employees behave during times of sustained crisis. Agility and resilience are measures of how we are able to adapt to change rapidly and 'bounce back' from hardship experienced during disruptive and rapidly changing contexts. They are, therefore, apt measures to do a temperature reading of agility and resilience.

Previous studies on agility across business fields have suggested that employee agility is a crucial component of organisational agility. Chonko and Jones (2009) suggested that organisational agility results from the people who comprise it working together in ways that benefit the individual, the organisation and their customers. As organisations begin to transition from the initial panic stage of shutdown to adaptions to work from home, with COVID-19, this creates a new reality. There is a need to understand the impact and responses of COVID-19 and the agility and resilience capacity of permanent employees in South Africa.

During the COVID-19 pandemic, much has been written about the importance of employee resilience and agility in terms of navigating unpredicted change, absorbing and adapting the challenges (Childress, 2020; Chong et al., 2020), ways to develop resilience and agility (Neuroleadership Institute, 2020) and leadership competence development after COVID-19 (Dirani et al., 2020). Yet there is an absence of research data providing a temperature reading on the current reality of employee agility and resilience in South Africa.

\section{Aim of the study}

The purpose of this study was to conduct a temperature reading of South African permanent employees' agility and resilience levels. Hence, the research question guiding the study is as follows: 'what are the employee agility and resilience levels of employees in South Africa?'

\section{Contribution to the field}

Much has been written about the concern of mental health of global citizens and the need for urgent wellness support (Pfefferbaum \& North, 2020; Xiang et al., 2020). For I-O psychology scholar-practitioners, there has been an urgent appeal to focus research within the COVID-19 pandemic on wellness, health and safety of the employees (Rudolph et al., 2020). In response to the quest, this research offers quantitative data on the current state, a 'temperature reading' of COVID-19 on employee agility and resilience in South Africa. Human resources and industrial organisational psychologists are uniquely positioned to provide guidance about how COVID-19 will likely impact employees and organisation by providing evidence-based recommendations for navigating the challenges and opportunities of this crisis. Whilst a temperature reading is more suggestive than conclusive in its findings, it is nonetheless an important intervention to understand a rapidly and currently evolving situation. It flags potential areas for $\mathrm{HR}$ and I-O scholars to hone in on to further unpack employees and agility of employees during periods of profound social disruption.

Thus, the starting point was to take a 'temperature reading' to determine the impact of COVID-19 on employee agility and resilience. For the purposes of this research, the constructs for agility and resilience at an individual level were based on the development, validation and practical application of an employee agility and resilience measure (Braun, Hayes, DeMuth, \& Taran, 2017), as the measure was used to take the 'temperature reading'. According to Braun et al. (2017), agility was defined as a skill of proactive rethinking or redefining to overcome obstacles. As defined by Bridges (1980) cited in Braun et al. (2017), resilience is 'the emotional and psychological transition to change'. We suggest that before organisations embark on their post-COVID-19 recovery plan to navigate the effects of the COVID-19 pandemic, it is important to know how this pandemic affects employees in South Africa.

\section{Research design and data analysis}

The quantitative, non-experimental research method was deemed most suitable to answer the research questions (Creswell \& Creswell, 2017). Both descriptive and inferential statistics were used in the data analysis. Using the indices from the survey, the study derived mean composite scores for each of the dimensions of agility and resilience. For example, in the case of agility, the responses to the five questions measuring agility were transformed into a single mean score representing the entire dimension of agility. 
This technique was conducted for all seven dimensions, which allowed for further analysis. Ordinary least squares (OLS) regression analysis was conducted on the dimensions of agility and resilience (DV) and demographics, employment and organisational characteristics, impact on employees and employees' responses to COVID-19 (IV) (Craven \& Islam, 2011).

\section{Research participants}

The population included all people permanently employed in South Africa. The sampling strategy utilised was nonprobability with a purposive design (Etikan, Musa, \& Alkassim, 2016). A total of 229 respondents completed the questionnaire; once the data were cleaned, the final sample size was $185(N=185)$.

\section{Measuring instruments}

The survey questionnaire comprised four parts. The researchers developed the first three parts; part 4 is a standardised measure. The four parts were as follows: (1) demographics, six questions covering age, gender, employment, education, work sector and organisational size; (2) impact of COVID-19 on employees, four questions on the impact of COVID-19 on workload, salary and feasibility to work from home and workspace; (3) employee response to COVID-19, three questions with a 1-5 Likert scale on the risk of job loss, need to outperform peers, organisational communication and one question with a nominal rating scale on upskilling because of COVID-19; and (4) the standardised instrument of Employee Agility and Resilience (Braun et al., 2017) measures 46 items with a 1-5 Likert scale across seven dimensions: agility (14 items), resilience (nine items), individual renewal (three items), collaboration (eight items), creating positive relationships (four items), openness to experience (three items) and social support (five items) (Braun at al., 2017). A measure of Cronbach's alpha was used to describe the internal consistency and reliability of the questions used to measure the above-mentioned psychometric constructs. Permission was granted to use the Employee Agility and Resilience survey instrument (T. Braun, pers. comm., 18 May 2020).

\section{Research procedures}

Once the LinkedIn gatekeeper letter was obtained, an application was submitted for ethical clearance from the University Research Office. The researchers placed a notice on LinkedIn, which contained information about the title, purpose, study procedures, time commitment to complete the questionnaire, the inclusion criteria used to determine eligibility, contact details for the researchers and a link to the SurveyMonkey questionnaire. Data collection was done from 25 June 2020 to 20 July 2020, and during this time period, South Africa was in lockdown level 3. All principles of anonymity, confidentiality and non-maleficence were adhered to in the study. Participation was voluntary. Respondents had to give informed consent for participating in the study and they were informed that they could withdraw from the study at any point without any consequences for themselves.

Once the survey was closed, the data were exported and analysed using Stata software program.

\section{Ethical considerations}

Ethical approval was obtained from the University of KwaZulu-Natal Humanities and Social Sciences Research and Ethics committee (ethical clearance number: HSSREC/00001423/2020).

\section{Results Demographics}

The majority of the sample comprised women $(55.68 \%)$, within the age group of $36-45$ years $(39.46 \%)$, living in KwaZulu-Natal (62.19\%) and had some form of tertiary education $(49.46 \%)$. The demographic, employment and organisational characteristics of the sample are presented in Table 1.

\section{Impact of COVID-19 on employees}

As part of a temperature research design, we were interested in whether respondents experienced any changes to their salaries and workloads. Additionally, with mandatory work from home policies being the norm during the pandemic, we wanted to assess constraints to remote working (if any). As such questions we designed were questions probing these areas. This section reports on the responses of those surveys on the impact of the pandemic on their workload, salaries and working from home constraints.

Most respondents (69.2\%) had experienced an increased, moderate and low increase in workload. Of the sample, $61.08 \%$ reported that the pandemic had no impact on their salaries. Of those individuals who reported that there was an impact on their salary (38.92\%), 72.22\% experienced a general pay reduction. The majority of respondents $(76.67 \%)$ reported that it was feasible for them to work from home. Of those that reported constraints to working from home, the majority $(50.88 \%)$ of the sample indicated that resources were a constraint, whilst $15.79 \%$ experienced space constraints and $17.54 \%$ experienced constraints related to privacy. Table 2 shows the results of the impact of COVID-19 on employees.

\section{Employee responses to COVID-19}

In this section, we report on employee responses to questions on perceptions of their job security, the pressure to outperform their peers to demonstrate their usefulness to their employers, the extent to which they were informed of organisational changes and whether they had considered upskilling as a strategy to demonstrate value to their organisations.

The results show that $44.51 \%$ (strongly disagree and disagree) of respondents feel that they are not at risk of losing their job, 
TABLE 1: Demographic, employee and organisational characteristics of the sample.

\begin{tabular}{|c|c|c|}
\hline Characteristics & $f$ & $\%$ \\
\hline \multicolumn{3}{|l|}{ Demographic characteristics } \\
\hline \multicolumn{3}{|l|}{ Gender } \\
\hline Male & 82 & 44.32 \\
\hline Female & 103 & 55.68 \\
\hline Total & 185 & 100.00 \\
\hline \multicolumn{3}{|l|}{ Age (years) } \\
\hline $18-25$ & 10 & 5.41 \\
\hline $26-35$ & 57 & 30.81 \\
\hline $36-45$ & 73 & 39.46 \\
\hline $46-55$ & 33 & 17.84 \\
\hline $56-65$ & 11 & 5.95 \\
\hline $66+$ & 1 & 0.54 \\
\hline Total & 185 & 100.00 \\
\hline \multicolumn{3}{|l|}{ Province } \\
\hline Eastern Cape & 3 & 1.62 \\
\hline Free state & 1 & 0.54 \\
\hline Gauteng & 42 & 22.70 \\
\hline KwaZulu-Natal & 115 & 62.16 \\
\hline Mpumalanga & 2 & 1.08 \\
\hline Limpopo & 2 & 1.08 \\
\hline Northern Cape & 0 & 0.00 \\
\hline North West & 1 & 0.54 \\
\hline Western Cape & 19 & 10.27 \\
\hline Total & 185 & 100.00 \\
\hline \multicolumn{3}{|l|}{ Educational level } \\
\hline Did not complete school & 3 & 1.63 \\
\hline Completed Grade 12 & 29 & 15.76 \\
\hline Tertiary education & 91 & 49.46 \\
\hline Master's degree or PhD & 61 & 33.15 \\
\hline No schooling & 0 & 0.00 \\
\hline Total & 184 & 100.00 \\
\hline \multicolumn{3}{|c|}{ Employee and organisational characteristics } \\
\hline \multicolumn{3}{|l|}{ Employment position } \\
\hline Admin & 19 & 10.27 \\
\hline Staff member & 77 & 41.62 \\
\hline Manager & 67 & 36.22 \\
\hline Director & 17 & 9.19 \\
\hline Owner & 4 & 2.16 \\
\hline Other & 1 & 0.54 \\
\hline Total & 185 & 100.00 \\
\hline \multicolumn{3}{|l|}{ Employment sector } \\
\hline Security/Police & 5 & 2.70 \\
\hline Marketing & 15 & 8.11 \\
\hline Sales & 10 & 5.41 \\
\hline State-owned enterprise & 2 & 1.08 \\
\hline Government & 6 & 3.24 \\
\hline Mining & 5 & 2.70 \\
\hline Agriculture, fishing and forestry & 2 & 1.08 \\
\hline Financial services & 25 & 13.51 \\
\hline Medical and healthcare & 15 & 8.11 \\
\hline Information technology & 10 & 5.41 \\
\hline Construction & 7 & 3.78 \\
\hline Professional services & 27 & 14.59 \\
\hline Manufacturing & 14 & 7.57 \\
\hline Education & 42 & 22.73 \\
\hline Total & 185 & 100.00 \\
\hline \multicolumn{3}{|l|}{ Organisational size } \\
\hline $1-50$ & 52 & 28.11 \\
\hline $51-200$ & 24 & 12.97 \\
\hline $201-500$ & 20 & 10.81 \\
\hline $501-1000$ & 14 & 7.57 \\
\hline $1001-5000$ & 32 & 17.30 \\
\hline $5001+$ & 41 & 23.24 \\
\hline Total & 185 & 100.00 \\
\hline \multicolumn{3}{|l|}{ Essential services } \\
\hline Yes & 107 & 57.84 \\
\hline No & 78 & 42.16 \\
\hline Total & 185 & 100.00 \\
\hline
\end{tabular}

TABLE 2: The impact of COVID-19 on employees.

\begin{tabular}{|c|c|c|}
\hline Variables & $f$ & $\%$ \\
\hline \multicolumn{3}{|l|}{ Impact of COVID-19 on workload } \\
\hline Increased & 84 & 45.41 \\
\hline Moderate increase & 34 & 18.38 \\
\hline Low impact increase & 10 & 5.41 \\
\hline Decrease & 37 & 20.00 \\
\hline No impact & 20 & 10.81 \\
\hline Total & 185 & 100.00 \\
\hline \multicolumn{3}{|l|}{ Impact of COVID-19 on salary } \\
\hline Yes & 72 & 38.92 \\
\hline No & 113 & 61.08 \\
\hline Total & 185 & 100.00 \\
\hline \multicolumn{3}{|l|}{ Type of impact on salary } \\
\hline General pay reduction & 39 & 72.22 \\
\hline Reduced work hours & 3 & 5.56 \\
\hline Reduction in output (manufacturing) & 1 & 1.85 \\
\hline Increase in pay & 1 & 1.85 \\
\hline Bonus, benefits and leave reduction & 6 & 11.11 \\
\hline Complete loss of income & 4 & 7.41 \\
\hline Total & 54 & 100.00 \\
\hline \multicolumn{3}{|l|}{ Feasible to work from home } \\
\hline Yes & 142 & 76.76 \\
\hline No & 43 & 23.24 \\
\hline Total & 185 & 100.00 \\
\hline \multicolumn{3}{|l|}{ Constraints to work from home } \\
\hline Space & 9 & 15.79 \\
\hline Resources & 29 & 50.88 \\
\hline Privacy & 10 & 17.54 \\
\hline Other & 9 & 15.79 \\
\hline Total & 57 & 100.00 \\
\hline \multicolumn{3}{|l|}{ Other constraints } \\
\hline I have to work onsite & 6 & 75 \\
\hline Prohibited because of lockdown regulations & 2 & 25 \\
\hline Total & 8 & 100.00 \\
\hline
\end{tabular}

COVID-19, coronavirus disease 2019.

whilst $34.06 \%$ of respondents agreed that they need to outperform their peers to survive in their respective jobs or organisations. An overwhelming majority of respondents $(67 \%)$ stated that they are well informed of organisational changes. More than $42 \%$ of respondents have considered upskilling in response to COVID-19, whilst $29.12 \%$ of the sample indicated that they have already started upskilling. The results are shown in Table 3.

\section{Employee agility and resilience}

The purpose of this section is to report how respondents scored on the dimensions of agility and resilience. Furthermore, we report the correlations between each of the dimensions of agility and resilience. The section ends with a reportage of the mean scores of agility and resilience.

The correlations of each of the dimensions of agility and resilience are shown in Table 4 . The results indicate that there is a medium correlation between agility and collaboration $(r=0.51, p<0.05)$, a medium correlation between agility and resilience $(r=0.48, p<0.05)$ and resilience and collaboration $(r=0.55, p<0.05)$, with a very weak correlation between agility and individual renewal $(r=0.02)$. The results show 
that the mean agility score for the sample is fairly agile $(M=20.11)$ with the lowest dimension of individual renewal $(M=10.22)$, as shown in Table 5 . The results suggest that the sample, on an average, score is higher on all the dimensions of agility and resilience.

\section{Regression model}

A regression model was used to determine the relationship between the dimensions of employee agility and resilience scores and each of the demographic variables, as shown in Table 6. The results showed that gender is not a significant predictor of agility. Employees aged 56-65 years are significantly less agile than those aged 36-45 years (-2.2069, $p<0.05)$. Directors are significantly more resilient than staff members (2.6487, $p<0.05)$. Regarding organisational size, employees who work in organisations with between 51 and 200 staff members are significantly more resilient than those who work in organisations with 0-50 staff members (1.9823, $p<0.05)$. Women are significantly less likely to participate in

TABLE 3: Employee responses to COVID-19.

\begin{tabular}{lcc}
\hline Variables & $f$ & \% \\
\hline Risk of losing job because of COVID-19 & \\
Strongly disagree & 44 & 24.18 \\
Disagree & 37 & 20.33 \\
Neutral & 52 & 28.57 \\
Agree & 30 & 16.48 \\
Strongly agree & 19 & 10.44 \\
Total & 182 & 100.00 \\
Outperform peers for survival & & \\
Strongly disagree & 40 & 21.98 \\
Disagree & 36 & 19.78 \\
Neutral & 44 & 24.18 \\
Agree & 32 & 17.58 \\
Strongly agree & 30 & 16.48 \\
Total & 182 & 100.00 \\
Well informed of changes & & \\
Strongly disagree & 17 & 9.34 \\
Disagree & 8 & 4.40 \\
Neutral & 35 & 19.23 \\
Agree & 49 & 26.92 \\
Strongly agree & 73 & 40.11 \\
Total & 182 & 100.00 \\
Upskilling in response to CoVID-19 & & \\
Yes & 78 & 42.86 \\
No & 51 & 28.02 \\
I have already started upskilling & & 29.12 \\
Total & & 100.00 \\
\hline COV & & \\
\hline
\end{tabular}

COVID-19, coronavirus disease 2019. individual renewal activities than their male counterparts $(-1.2851, p<0.05)$. The results show that employment, organisational size and impact of COVID-19 on employees are significant predictors of the various dimensions of agility and resilience.

Regression analysis was conducted to determine the relationship between dimensions of employee agility and resilience and employee responses to COVID-19, as shown in Table 7. The regression models in Table 7 test the relationships between the dimensions of agility and resilience and the various employee responses to COVID-19. The results show that individuals who believe that they are at risk of losing their jobs because of COVID-19 have significantly less social support than those who are neutral to their perception of job loss $(-1.6154, p<0.05)$, and those who feel that they are at risk of losing their jobs are also significantly less likely to spend time in individual renewal than their counterparts $(-1.3906, p<0.05)$. The results show that those who are well informed about organisational changes are significantly more resilient, create more positive relationships and are more open to experience than those who reported being neutral about being well informed (1.4163, 1.5327 and 0.6498, respectively, $p<0.05$ ). Individuals who have already started upskilling have more social support and are more open to experience than their counterparts who have not thought about upskilling because of COVID-19 (1.3311 and 0.6077, respectively, $p<0.05$ ).

\section{Discussion}

\section{Explaining high employee agility and resilience levels}

This section offers possible explanations for the relatively high levels of resilience and agility of the study sample. We report first on the levels of resilience and agility and offer six possible reasons for why, despite the various challenges of the pandemic on workers globally, South African

TABLE 5: Scores of agility and resilience.

\begin{tabular}{lccccc}
\hline Variables & Mean score & Standard error & Min & Max & $f$ \\
\hline Agility & 20.11 & 0.227 & 5 & 25 & 171 \\
Resilience & 24.46 & 0.248 & 6 & 30 & 171 \\
Collaboration & 20.57 & 0.197 & 5 & 25 & 171 \\
Creating positive relationships & 25.84 & 0.232 & 6 & 30 & 171 \\
Social support & 19.80 & 0.256 & 5 & 25 & 171 \\
Individual renewal & 10.22 & 0.215 & 3 & 15 & 169 \\
Openness to experience & 12.42 & 0.115 & 3 & 15 & 171 \\
\hline
\end{tabular}

TABLE 4: Correlation between the dimensions of agility and resilience.

\begin{tabular}{|c|c|c|c|c|c|c|c|c|c|}
\hline Variables & Mean & Standard deviation & 1 & 2 & 3 & 4 & 5 & 6 & 7 \\
\hline Agility & 20.11 & 2.97 & 0.78 & - & - & - & - & - & - \\
\hline Resilience & 24.46 & 3.24 & $0.48 *$ & 0.83 & - & - & - & - & - \\
\hline Collaboration & 20.57 & 2.58 & $0.51 *$ & $0.55^{*}$ & 0.74 & - & - & - & - \\
\hline Creating positive relationships & 25.84 & 3.03 & $0.36 *$ & $0.45^{*}$ & $0.52 *$ & 0.86 & - & - & - \\
\hline Social support & 19.80 & 3.35 & $0.20 *$ & $0.25^{*}$ & $0.37 *$ & $0.50 *$ & 0.81 & - & - \\
\hline Individual renewal & 10.22 & 2.80 & 0.02 & 0.14 & 0.13 & 0.15 & $0.24 *$ & 0.77 & - \\
\hline Openness to experience & 12.42 & 1.50 & $0.30 *$ & $0.42 *$ & $0.42 *$ & $0.43 *$ & $0.23 *$ & $0.15^{*}$ & 0.70 \\
\hline
\end{tabular}

Note: Figures in parenthesis are internal reliability estimates (Cronbach's alpha).

$*$, Denotes a statistical significance at $95 \%$ level of confidence $(p<0.05)$. 


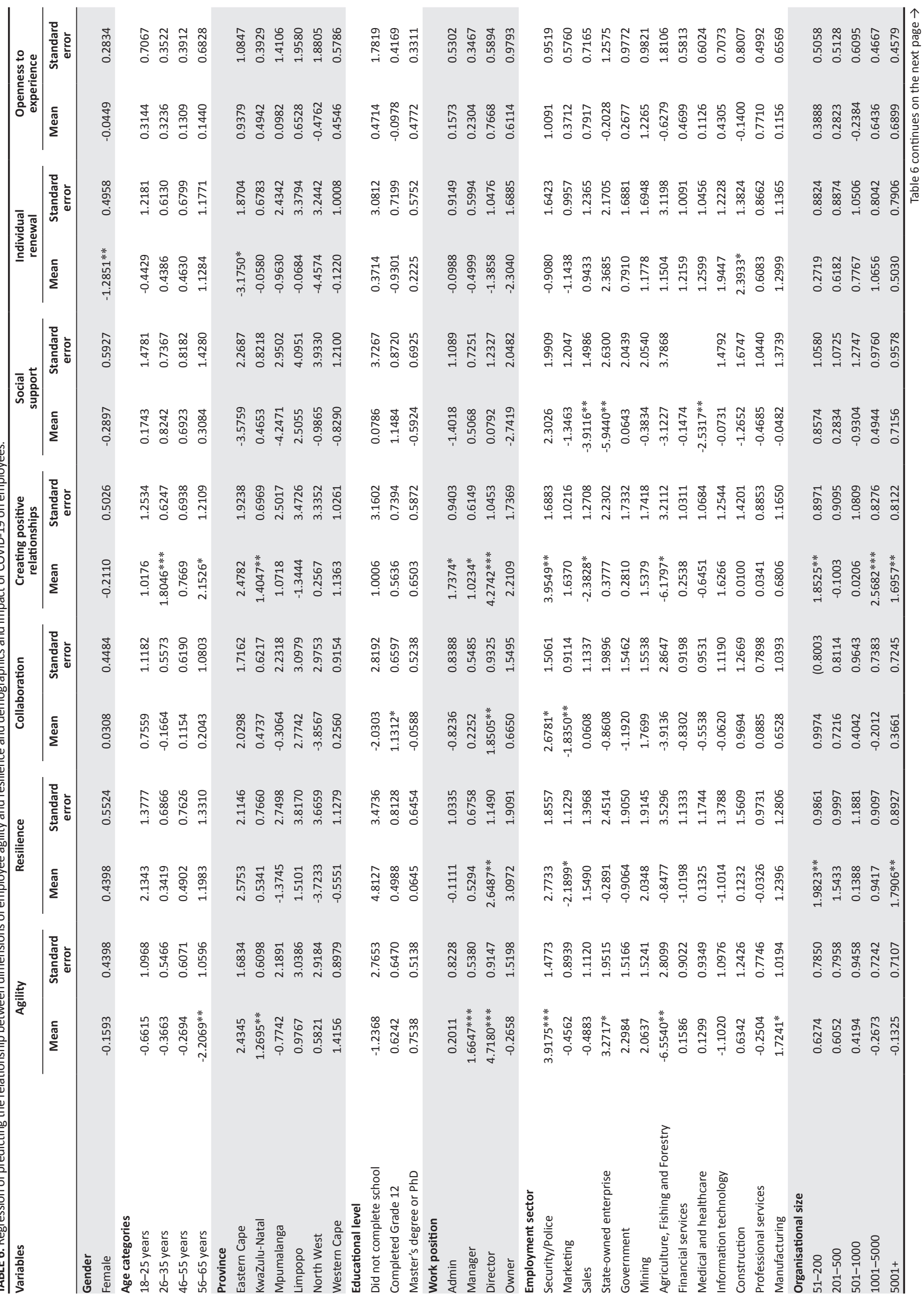




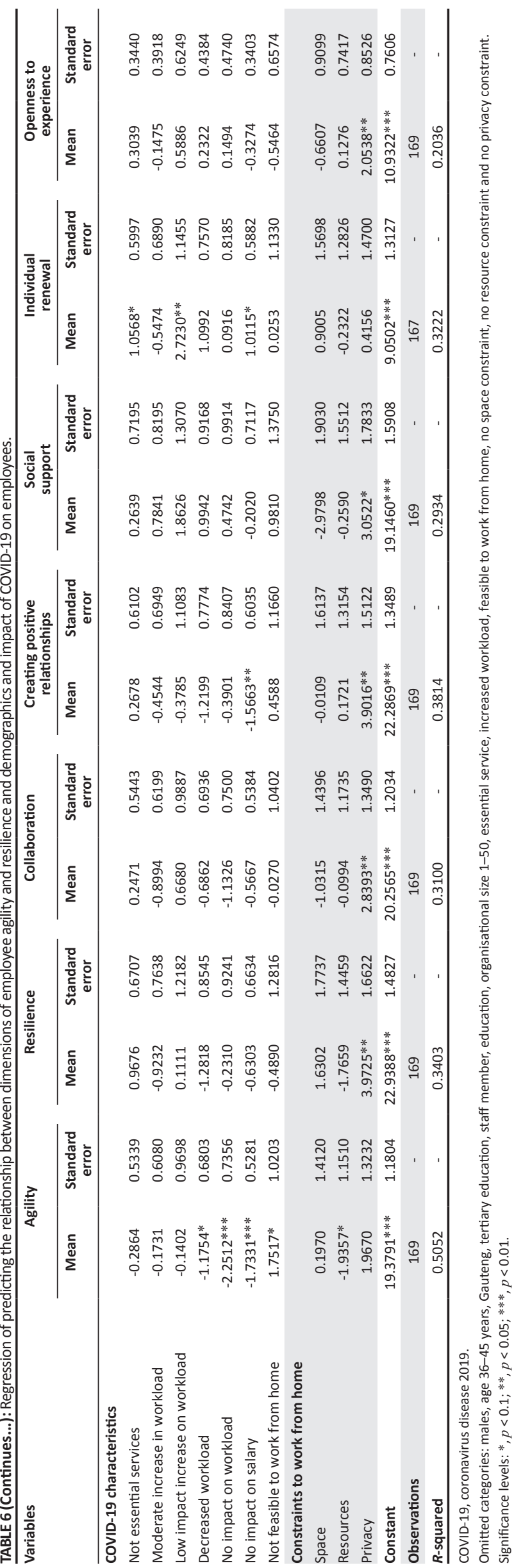

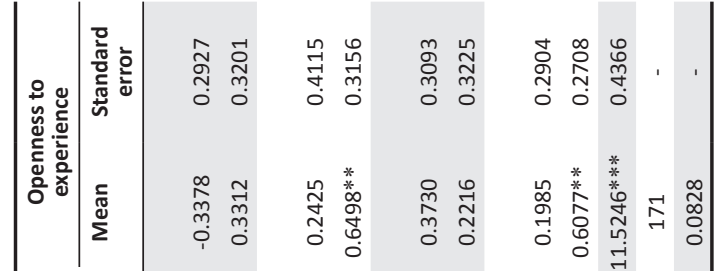

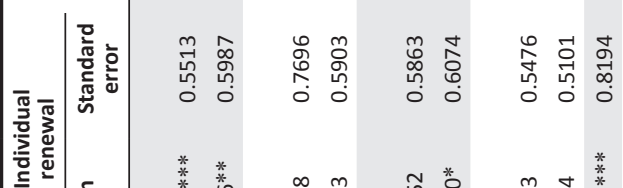

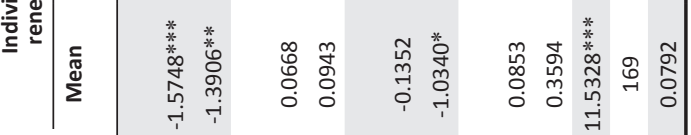

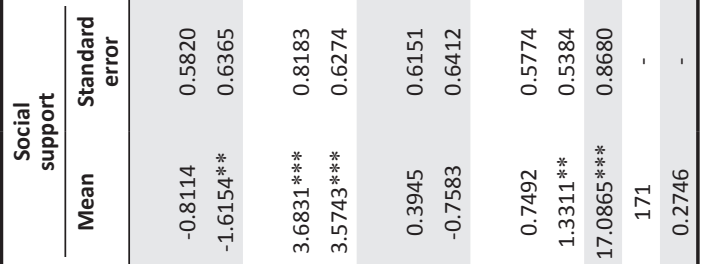

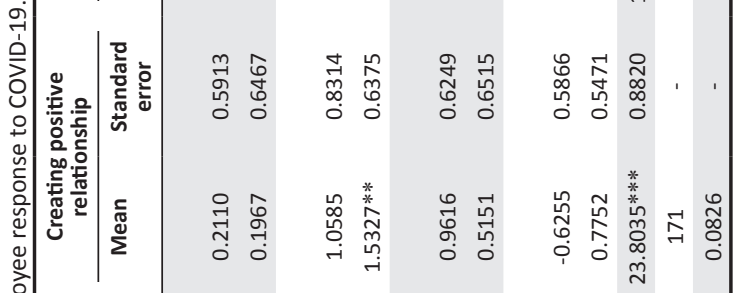

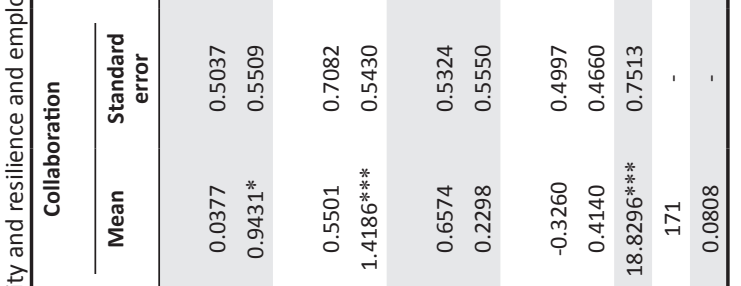

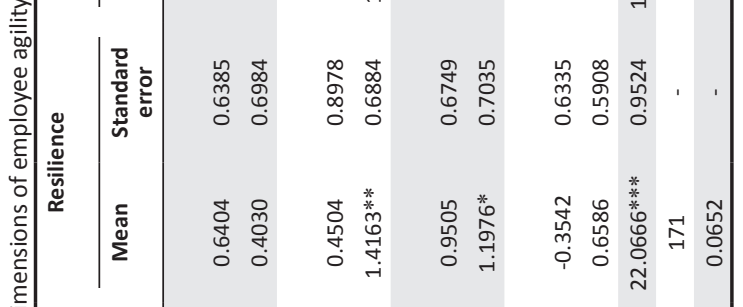

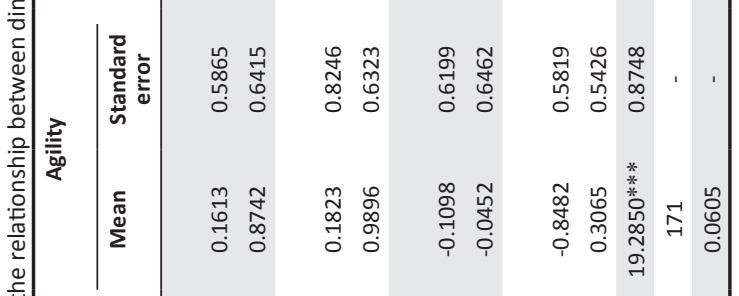

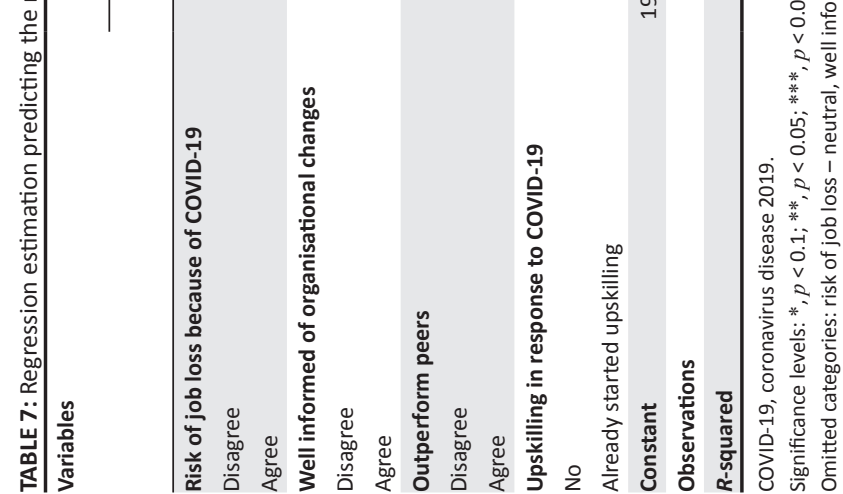


employees scored relatively high on both agility and resilience scores.

The findings show that out of a lowest possible score of 5 and a highest possible score of 25 , the mean agility score was 20.11 and the mean resilience score was 24.46 . These results were unexpected given the literature showing that employees are struggling on both these measures, especially in Europe and North America (Barzilay et al., 2020; Hite \& McDonald, 2020). This presents a challenge to our conjecture that the hardships of the pandemic would impact negatively employees' levels of agility and resilience. The first possible reason for this may be that extant pre-pandemic social, political and economic hardships faced by South Africans have an inoculating effect on their resilience and agility levels.

For example, research has shown that South Africans are more 'can-do' in terms of their attitude, enjoy high levels of resilience and are globally employees of choice (The South African, 2016). Another example of this can be found in a recent survey of South African millennials. Millennials in the survey scored higher on the mood index than their global counterparts (Deloitte Consulting, 2020). A second possibility in explaining the relatively high levels of resilience and agility may be related to the nature of the sample. The fact that the sample size was a cohort of permanently employed South Africans could mean that they felt relatively secure in their jobs, and in an attempt to maintain this security, they were willing and able to adapt to new work organisation demands.

Thirdly, the majority of participants were from the education $(23 \%)$ and professional services sector (14\%) with high levels of tertiary education. These are sectors that require to have relative stability during the pandemic in terms of job security. Employees in these sectors would also be highly credentialed, which may give them a sense of being less vulnerable in the labour market. Additionally, the nature of the education and professional services sectors also mean that they are better positioned to catalyse employee's agility and resilience levels through training, development and support initiatives.

Fourthly, over $45 \%$ of the participants were in management positions. Cumulatively, this meant that this cohort of the sample were highly credentialed and experienced in organisational life and therefore better prepared to adapt and cope with organisational change. They would have had prior experiences of organisational and personal stress as well as methods to mitigate this. South Africa's prepandemic normative context of uncertainty in the economy characterised by high unemployment, rolling power outages, adversarial labour relations framework and prior HIV and TB epidemics would also have had some influence on honing employee's agility and resilience levels. Organisational learning during these conditions would have served a protective function despite the amplification of restructuring and remote working policies, especially.
Agility traits such as the ability to assess the dynamics of the workplace and the ability to adapt to organisational change could be the outcome of prior organisational learning experiences.

Fifthly, literature suggests that respondents may score themselves higher on these dimensions if it reflects positively on their perceptions of self-worth. Finally, $58 \%$ of our sample identified themselves as essential workers. Employees in essential services are less likely to be retrenched or fired. This, therefore, may have also impacted the high agility and resilience scores, given that essential workers would feel greater job security than those not classified as essential during the pandemic.

\section{Employees' responses to COVID-19}

The previous section offered conjectures as to why respondents scored relatively high resilience and agility levels. This section analyses the sample's responses with regard to gender, age, size of organisation and work organisation.

\section{Gender, agility and resilience}

The results show that gender is not a significant predictor of agility. Importantly, the analysis showed that women are significantly less likely to participate in individual renewal activities than males. Individual renewal is the behavioural action of self-care, where breaks are taken to build and renew capacity. According to Gill and Orgad (2018), women are under increased social pressure to be agile and resilient in order to be perceived as successful. The extra gendered (child care, emotional labour, domestic work, and negotiating patriarchy on a daily basis) work that women engage in often builds their resiliency and agility levels, more so than men. This finding challenges the perception that women are more likely to engage in self-care activities than men, because self-care is stereotypically viewed as a feminine activity. However, it also implies that women are most likely to engage in care activities of others including partners and children at the expense of their own care. Studies have shown that women are disproportionately bearing the brunt of the remote work policies of organisations during the pandemic (Power, 2020). This double burden on women is regardless of their rank at work (Alon, Doepke, OlmsteadRumsey, \& Tertilt, 2020; Minello, 2020). This has implications for how and where psychological support is offered in organisations, especially as most organisations are focusing on gender equality and inclusion.

\section{Age, agility and resilience}

Our study further shows that individuals aged 56-65 years are significantly less agile than those aged 36-45 years $(-2.2069, p<0.05)$. This is in line with studies that showed that younger people tend to be more agile and resilient (Muduli, 2013). Older employees may be less open to change 
and have fewer support mechanisms for resilience despite greater experiential learning.

\section{Organisational size, agility and resilience}

Respondents who work in organisations with between 51 and 200 staff members are significantly more resilient than those who work in organisations with 0-50 staff members (1.9823, $p<0.05)$. Moreover, individuals who work in organisations with 5001 or more staff members have a significantly higher resilience than those who work in organisations with 0-50 staff members $(1.7906, p<0.05)$. This is in line with the conjecture that larger organisations offer more tangible support for all dimensions of agility and resilience, especially collaboration, support, networking and resilience training. Larger organisations are more likely to have dedicated human resources functions that facilitate employee resilience and agility, such as employee wellness programmes or dedicated training opportunities for staff. The concern, however, then remains for small to medium enterprises (SMMEs) that may not have the resources or know how to support mental and emotional well-being of employees. Given the centrality of the SMME sector for South Africa's economic growth, this is an area of concern.

\section{Impact on work organisation}

With regard to impact on employment, our results show that the majority of respondents (45\%) experienced a high increase in workload. This is in line with similar studies conducted globally (Kramer \& Kramer, 2020). At the same time, 20\% of respondents reported a decrease in workload. The inclination to upskill may be related to increased workload across multiple skill sets. Surprisingly, only 39\% of employees experienced an impact on their salaries, but this may be related to the nature of the sectors they work in. Impact on salary mainly consisted of a general pay reduction. The majority of the sample (77\%) indicated that they were able to work from home despite the constraints of resources, privacy and space. The largest constraint reported was lack of resources.

Given the temperature reading design of the study, we aimed to obtain an empirical 'snapshot' of the agility and resilience levels of employees as well as to report on their responses to questions on work organisation during the pandemic. This section has focused on four key areas of gender, age, organisation size and the impact of workload which inform tailored practical implications for $\mathrm{I} / \mathrm{O}$ psychologists.

\section{Limitations}

As with all research, this study has limitations and the following should be taken into account when reviewing the research results. The convenience sample that was used to gather self-report data from permanent employees via LinkedIn was biased to professional employees within the KwaZulu-Natal province. A further limitation was the self- report measures, which may have impacted the results as the sample may have given favourable responses. Nevertheless, the study provides useful and important insights, a 'temperature reading', into the impact of COVID-19 on employee agility and resilience in South Africa. In addition, caution should be made to generalise these findings as the COVID-19 circumstances are different in each country.

As this was an exploratory 'temperature reading' study, future research should apply more representative sampling techniques to access a generalisable sample of the general population. As organisations enter into the COVID-19 recovery strategy, there will be merit in adding measures of employee wellness to track the individual renewal dimension as well as leadership and organisational culture as mediating and moderating variables, ultimately, in a longitudinal research study.

\section{Implications for the profession}

The high-level practical implications are to use the 'temperature reading' results to raise awareness of employees' own agility and resilience and then build interventions, especially in the COVID-19 employee-care and organisation recovery plan. Recently, there has been a dearth of resilience-building self-help; in the absence of organisational authentic empathy, these self-help initiatives can perpetuate the 'us and them divide', which exists in some organisations. Based on these results, the specific practical applications would be to:

- Continue to communicate to employees as this has a significant impact on resilience, collaboration, creating positive relationships.

- Support women employees with tailored individual renewal activities.

- Utilise the age group of 26-35 years employees to expand positive relationships across organisations.

- Set up resilience mentor collaborative partnerships, the larger organisations, especially, directors, who have high resilience scores to partner with organisations of size 1-200. This is a vital offering, especially given the large number of SMME businesses in South Africa.

\section{Conclusions}

The overarching purpose of this article was to determine employee agility and resilience capacity during the COVID-19 pandemic and understand employees' responses to the pandemic in South Africa. The research findings contribute to the knowledge base and practice of I-O psychology. These results add value for leaders, I-O psychologists and HR professionals who are either reviewing or starting their post-COVID strategies, highlighting the vital focus on tailored employee agility and resilience solutions with partnerships. HR and I-O professionals are in important positions within academia and organisations in South Africa in order to design and 
implement employee agility and resilience evidence-based initiatives using empirical data.

\section{Acknowledgements}

The authors thank all the respondents for giving their time generously to participate in the study.

\section{Competing interests}

The authors declare that they have no financial or personal relationships that may have inappropriately influenced them in writing this article.

\section{Authors' contributions}

Both C.L. and S.R. developed the research questions, aim of the study, designed the methodology and wrote the manuscript. S.R. funded the fieldwork and C.L. provided and developed the research instruments.

\section{Funding information}

This research received no specific grant from any funding agency in the public, commercial or not-for-profit sectors.

\section{Data availability}

All data are available publicly at http:/ /dx.doi.org/10.23668/ psycharchives.4323.

\section{Disclaimer}

The views and opinions expressed in this article are those of the authors and do not necessarily reflect the official policy or position of any affiliated agency of the authors.

\section{References}

Alon, T., Doepke, M., Olmstead-Rumsey, J., \& Tertilt, M. (2020). This time it's different: The role of women's employment in a pandemic recession. National Bureau of Economic Research, No. w276602020. Retrieved from http://www.nber.org/ papers/w27660

Alves, J.C., Lok, T.C., Luo, Y., \& Hao, W. (2020). Crisis management for small business during the COVID-19 outbreak: Survival, resilience and renewal strategies of firms in Macau. https://doi.org/10.21203/rs.3.rs-34541/v1

Bacq, S., Geoghegan, W., Josefy, M., Stevenson, R., \& Williams, T.A. (2020). The COVID-19 virtual idea blitz: Marshaling social entrepreneurship to rapidly respond COVID-19 virtual idea blitz: Marshaling social entrepreneurship to rapidly respond
to urgent grand challenges. Business Horizons, 63(6), 705-723. https://doi. to urgent grand challenges. Busine

Balmford, B., Annan, J.D., Hargreaves, J.C., Altoè, M., \& Batemen, I.J. (2020). Crosscountry comparisons of COVID-19: Policy, politics and the price of life Environmental and Resource Economics, 76, 525-551. https://doi.org/10.1007/ s10640-020-00466-5

Bardoel, E.A., Pettit, T.M., De Cieri, H., \& McMillan, L. (2014). Employee resilience: An emerging challenge for HRM. Asia Pacific Journal of Human Resources, 52(3) 279-297. https://doi.org/10.1111/1744-7941.12033

Barzilay, R., Moore, T.M., Greenberg, D.M., DiDomenico, G.E., Brown, L.A., White, L.K. et al., (2020). Resilience, COVID-19-related stress, anxiety and depression during the pandemic in a large population enriched for healthcare providers. Translational Psychiatry, 10, 291. https://doi.org/10.1038/s41398-020-00982-4

Braun, T.J., Hayes, B.C., DeMuth, R.L.F., \& Taran, O.A. (2017). The development, validation, and practical application of an employee agility and resilience measure
to facilitate organizational change. Industrial and Organizational Psychology, 10(4), 703-723. https://doi.org/10.1017/iop.2017.79

Breu, K., Hemingway, C.J., Strathern, M., \& Bridger, D. (2002). Workforce agility: The new employee strategy for the knowledge economy. Journal of Information Technology, 17(1), 21-31. https://doi.org/10.1080/02683960110132070

Cant, M.C. (2020). Employee engagement and performance: A study of South African retail organisations circa COVID-19. The Retail and Marketing Review, 16(3), 58-67. Retrieved from https://hdl.handle.net/10520/ejc-irmr1 v16-n3-a6
Childress, R. (2020). How staff agility and resilience is tied to organisational success through pandemic. Retrieved from https://associationsnow.com/2020/09/staffagility-resilience-tied-organizational-success-pandemic/

Chong, E., Handscomb, C., Williams, Q., Hall, R., \& Rooney, M. (2020). Agile resilience in the UK: Lessons from COVID-19 for the 'next normal'. Retrieved from https:// www.mckinsey.com/business-functions/organization/our-insights/agileresilience-in-the-uk-lessons-from-covid-19-for-the-next-normal

Chonko, L.B., \& Jones, E. (2005). The need for speed: Agility selling. Journal of Personal Selling \& Sales Management, 25(4), 371-382.

Cozby, P.C., \& Bates, S.C. (2015). Methods in behavioral research (12th edn.). New York, NY: McGraw-Hill.

Craven, B.D., \& Islam, S.M. (2011). Ordinary least-squares regression. CA, USA.

Creswell, J.W., \& Creswell, J.D. (2017). Research design: Qualitative, quantitative, and mixed methods approaches. CA, USA.

Deloitte Consulting. (2019). Deloitte global millennial survey: A "generation disrupted" south africa results. Retrieved from https://www2.deloitte.com/content/dam/ Deloitte/za/Documents/about-deloitte/za_deloitte_may_2019_millennials south_africa_report_f.pdf

Dirani, K.M., Abadi, M., Alizadeh, A., Barhate, B., Garza, R.C., Gunasekara, N., .. Majzun, Z. (2020). Leadership competencies and the essential role of human resource development in times of crisis: A response to COVID-19 pandemic. Human Resource Development International, 23(4), 380-394. https://doi.org/10. 1080/13678868.2020.1780078

Etikan, I., Musa, S.A., \& Alkassim, R.S. (2016). Comparison of convenience sampling and purposive sampling. American Journal of Theoretical and Applied statistics, 5(1), 1-4. https://doi.org/10.11648/j.ajtas.20160501.11

Gill, R., \& Orgad, S. (2018). The amazing bounce-backable woman: Resilience and the psychological turn in neoliberalism. Sociological Research Online, 23(2), 477-495. psychological turn in neoliberalism. Sociologic
https://doi.org/10.1177/1360780418769673

Havnen, A., Anyan, F., Hjemdal, O., Solem, S., Riksfjord, M.G., \& Hagen, K. (2020). Resilience moderates negative outcome from stress during the COVID-19 pandemic: A moderated-mediation approach. International Journal of Environmental Research and moderated-mediation approach. International Journal of Environmenta/

Helgeson, J., Fung, J., Zhang, Y., Roa, A., Zycherman, A., Nierenberg, C., ... Ramkissoon, D. (2020). Eliciting lessons from Small-and Medium-Sized Enterprises (SMEs) for natural disaster resilience planning and recovery during the COVID-19 pandemic: SME complex event resilience, other. Gaithersburg, MD: National Institute of SME complex event resilienc
Standards and Technology.

Hite, L.M., \& McDonald, K.S. (2020). Careers after COVID-19: Challenges and changes. Human Resource Development International, 23(4), 427-437. https://doi.org/10. 1080/13678868.2020.1779576

Kalidas, S., Magwentshu, N., \& Rajagopaul, A. (2020). How South African SMEs can survive and thrive post COVID-19. Retrieved from https://www.mckinsey.com/ featured-insights/middle-east-and-africa/how-south-african-smes-can-surviveand-thrive-post-covid-19\#

Kramer, A., \& Kramer, K.Z. (2020). The potential impact of the Covid-19 pandemic on occupational status, work from home, and occupational mobility. Journal of Vocational Behavior, 119(1), 103442. https://doi.org/10.1016/j.jvb.2020.103442

Lamb, G. (2019). Social cohesion and violence in South Africa: Constructing a puzzle with missing pieces. Crime, Law and Social Change, 72(4), 365-385. https://doi. org/10.1007/s10611-019-09828-7

Lengnick-Hall, C.A., Beck, T.E., \& Lengnick-Hall, M.L. (2011). Developing a capacity for organizational resilience through strategic human resource management. Human organizational resilience through strategic human resource management. Human
Resource Management Review, 21(3), 243-255. https://doi.org/10.1016/j. Resource Managem

Matli, W. (2020). The changing work landscape as a result of the Covid-19 pandemic: Insights from remote workers life situations in South Africa. International Journal of Sociology and Social Policy, 40(9/10), 1237-1256. https://doi.org/10.1108/ IJSSP-08-2020-0386

Minello, A. (2020, April 17). The pandemic and the female academic. Worldview. Retrieved from http://covidacademics.co.za/Uploads/docs/The-pandemic-andthe-female-academic.pdf

Muduli, A. (2013). Workforce Agility: A review of literature. IUP Journal of Management Research, 12(3), 55-65.

Neuroleadership Institute. (2020, August 4). Navigating through crisis FAQ: What science says leaders should do [Blog post]. Retrieved from https://neuroleadership. com/your-brain-at-work/coronavirus-faq-what-science-says-leaders-should-do/

Ozili, P.K., \& Arun, T. (2020). Spillover of COVID-19: Impact on the global economy. Retrieved from https://mpra.ub.uni-muenchen.de/99850/

Peltzer, K. (2000). Trauma symptom correlates of criminal victimization in an urban community sample, South Africa. Journal of Psychology in Africa; South of the Sahara, the Caribbean, and Afro-Latin America, 10(1), 49-62.

Pfefferbaum, B., \& North, C.S. (2020). Mental health and the COVID-19 pandemic. New England Journal of Medicine, 383, 510-512. https://doi.org/10.1056/ NEJMp2008017

Podsakoff, N.P., Whiting, S.W., Podsakoff, P.M., \& Blume, B.D. (2009). Individual-and organizational-level consequences of organizational citizenship behaviors: A meta-analysis. Journal of Applied Psychology, 94(1), 122-141. https://doi. org/10.1037/a0013079

Power, K. (2020). The COVID-19 pandemic has increased the care burden of women and families. Sustainability: Science, Practice and Policy, 16(1), 67-73. https://doi. org $/ 10.1080 / 15487733.2020 .1776561$

Qin, R., \& Nembhard, D.A. 2010. Workforce agility for stochastically diffused conditions - A real options perspective. International Journal of Production Economics, 125(2), 324-334. https://doi.org/10.1016/j.ijpe.2010.01.006 
Rotolo, C.T., Church, A.H., Adler, S., Smither, J.W., Colquitt, A.L., Shull, A.C., ... \& Foster, G. (2018). Putting an end to bad talent management: A call to action for the field of industrial and organizational psychology. Industrial and Organizational
Psychology, 11(2), 176-219. https://doi.org/10.1017/iop.2018.6

Rudolph, C., Allan, B., Clark, M., Hertel, G., Hirschi, A., Kunze, F., ... Zacher, H. (2020 May 22). Pandemics: Implications for research and practice in industrial and organizational psychology. PsyArXiv. https://doi.org/10.31234/osf.io/k8us2

Statistics South Africa. (2020a). How unequal is South Africa. Retrieved from http:// www.statssa.gov.za/?p=12930

Statistics South Africa. (2020b). SA loses more than 600K formal sector jobs during COVID-19 lockdown. Retrieved from http://www.statssa.gov.za/?p=13690

The South African. (2016, April 25). Why south Africans make the best employees overseas. Retrieved from https://www.thesouthafrican.com/lifestyle/southafricans-abroad/why-south-africans-make-the-best-employees-overseas/
Urban, B., \& Ndou, B. (2019). Informal entrepreneurship: A focus on South African township entrereteneurship. Journal of Developmental Entrepreneurship, 24(4), 1950021. https://doi.org/10.1142/S1084946719500213

Van Zyl, L.E., \& Junker, N.M. (2019). Debating the scientific credibility of industrial and organisational psychology: A rebuttal. SA Journal of Industrial Psychology, 45, a1766. https://doi.org/10.4102/sajip.v45i0.1766

Warner, R., \& April, K. (2012). Building personal resilience at work. Effective Executive, 15(4), 53-68. Retrieved from http://affinityhealthhub.co.uk/d/attachments/1warner-april-1515408836.pdf

Xiang, Y.T., Yang, Y., Li, W., Zhang, L., Zhang, Q., Cheung, T., \& Ng, C.H. (2020). Timely mental health care for the 2019 novel coronavirus outbreak is urgently needed. The Lancet Psychiatry, 7(3), 228-229. https://doi.org/10.1016/S22150366(20)30046-8 